\title{
Incision Lines on the Female Breast
}

\author{
Andreas M. Skaria \\ Centre de Dermatochirurgie, University of Bern, Vevey, Switzerland
}

The direction of incision lines on the body are controversially discussed in surgical literature. Different approaches to the body and extremities have resulted in two contradicting theories widely found in the literature. Langer's lines, defined as "Spaltrichtungen" or cleavage lines, lie partially in line with the underlying muscle fibres. Kraissl's dynamic lines, as well as the Borges relaxed skin tension lines, suggest that incision lines should be placed perpendicular to the direction of the underlying muscles [1-3]. All these recommendations are entirely based on static or anatomical observations, without giving due consideration to other influencing factors such as active movement, tension, gravity, and ageing.

Various authors have shown that perpendicular tension on a scar will create dehiscence [4]. Micro-movements and micro-tension are the main causes of stimulating myofibroblasts to produce collagen, which results in a hypertrophic scar $[4,5]$. Immobilization and avoidance of perpendicular tension on a scar is one of the main factors in preventing hypertrophy [4]. Tension in the line of the scar minimizes hypertrophy and dehiscence in mice and in humans on the limbs $[5,6]$. There is limited literature about incision/excision lines on the female breast, and only Langer [1] and Kraissl [3] have really dealt with the subject. Langer suggested concentric excision lines around the nipple, whereas Kraissl proposed horizontal dome-shaped excision lines (Fig. 1). Both Langer and Kraissl showed two contradicting approaches without taking into account physiological ageing, differences in

$\begin{aligned} & \text { karger@karger.com } \\ & \text { www.karger.com/drm }\end{aligned}$
Karger

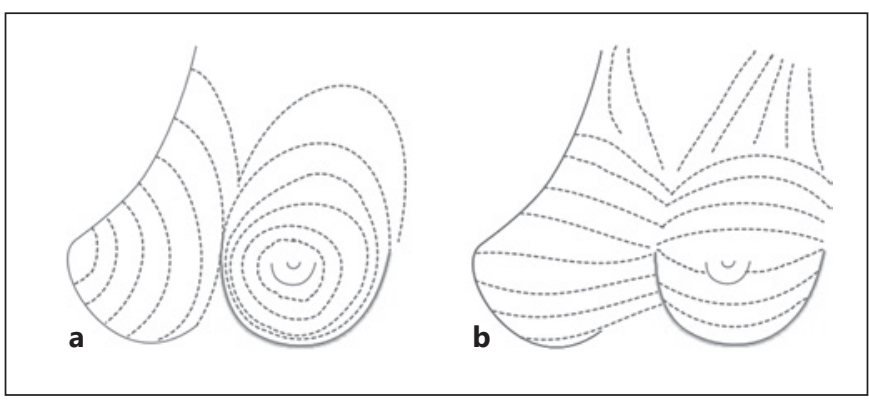

Fig. 1. Langer (a) and Kraissl (b) postulated the incision lines in the female breast in opposite ways. Langer suggested concentric incision lines whereas Kraissl described horizontal lines.

shape, and the effect of gravity $[1,3]$. These approaches were based solely on the static condition of a lying or sitting woman. However, they do not take into consideration the factors of movement and physical activity. Daytime activity is linked to physical movement, which is mostly walking or upright sitting, and has an important vertical tension factor on the skin of the breast. Nighttime sleep generates tension from various directions due to changing positions during the night. Lying on the back creates very strong tension forces on the medial parasternal part of the bust. Finally, tension is almost unavoidable in an excision on the female breast, but correct orientation can optimize tension in the line of the scar. An additional concern is physiological breast ptosis, as different
Andreas M. Skaria

Centre de Dermatochirurgie University of Bern $\mathrm{CH}-1800$ Vevey (Switzerland)

E-Mail skaria@vtxnet.ch 


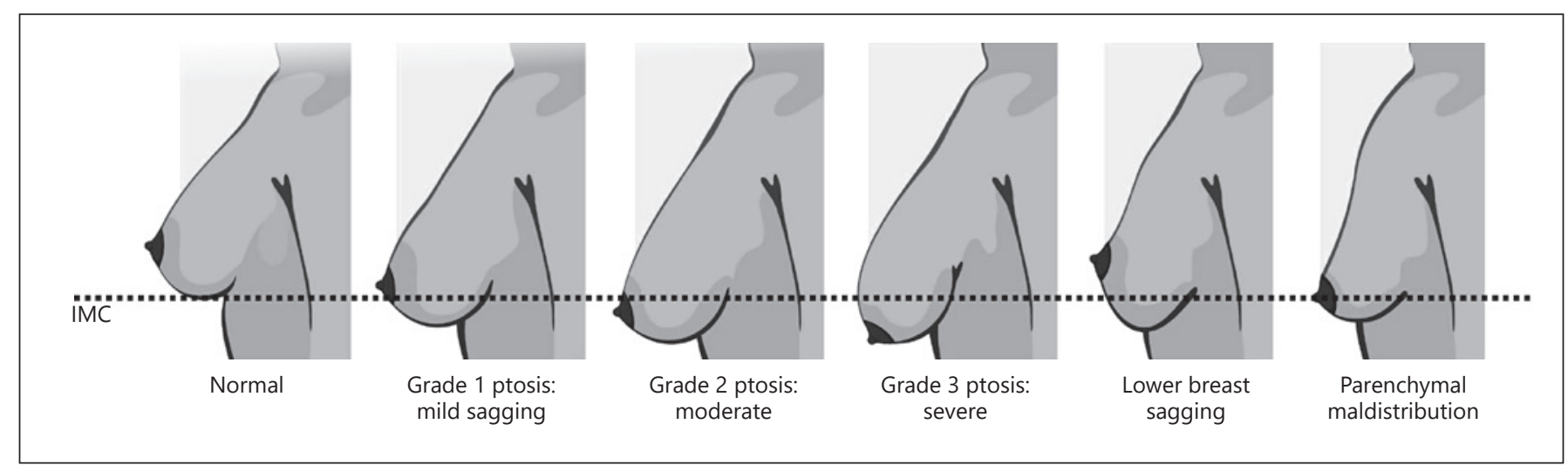

Fig. 2. Breast ptosis according to Regnault. The breast shows increasing sagging with the nipple descending under the inframammary crease (IMC) line. Grade 2 or 3 ptosis and lower breast sagging as well as parenchymal maldistribution increase the anterior posterior curvature of the breast.

Fig. 3. a-c. Incision lines should be adapted to the form of the breast. Ptosis increases the anterior posterior curvature line and incisions should be performed concentric horizontal in the underbreast.

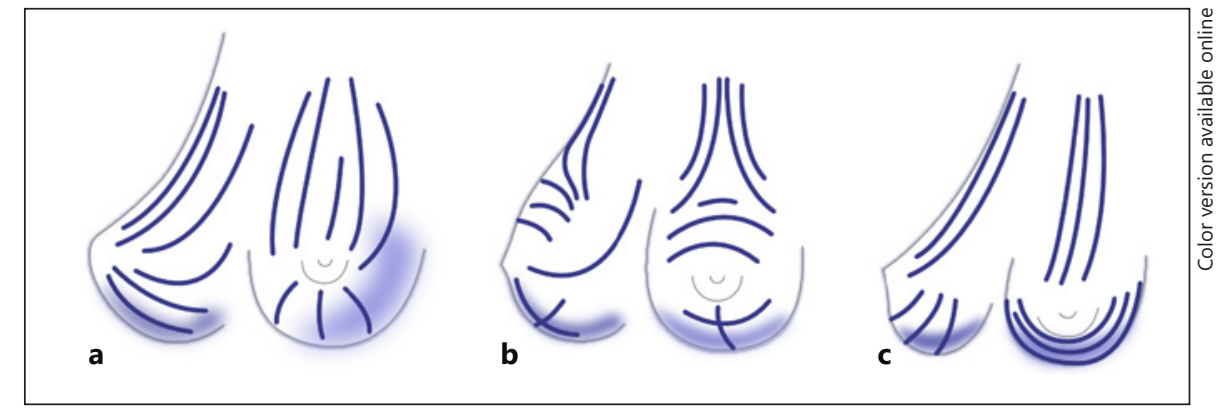

shapes of the breast are an important parameter in deciding on the incision line. Regnault [7] tried to classify the constitutional or ageing-related ptosis of the breast and established a breast ptosis scale (Fig. 2). With increasing ptosis and sagging the nipple descends below the inframammary crease (IMC) and the anterior posterior curvature of the lower part of the breast diminishes. In consequence, tension forces on the skin change. Because of the force of gravity on the upper part of the breast, vertical excisions are reasonable in this region [7]. A normal breast and ptosis grade 1 (the nipple is at the level of or above the IMC and above most of the lower breast tissue) corresponds to the surgical approach in Figure 3a, with a vertical excision on the upper breast and a vertical excision on the lower breast. Vertical excision means radial in relation to the nipple of the breast. In a full breast (after mammoplasty or naturally in very young patients; Fig. 3b), more concentric horizontal excisions in the lower upper part will release perpendicular tension on the scar as the mammary tissue below the nipple functions as a pillar to support the upper part of the breast. On the lower breast, either vertical radial or concentric horizontal excisions might be possible in this breast form in consideration of the curvature (Fig. 3b). The incision should always be in line with the lower curvature to keep the incision line short and decrease tension on the wound edge. In a breast with ptosis (Fig. 3c) where the nipple is lower than the IMC, only a vertical excision should be done in the upper breast with horizontal excisions on the lower breast due to the high anterior posterior curvature in the lower part.

In breast surgery the postoperative follow-up is extremely important. As the tissue is supple without close bonding to the underlying muscle, immobilization during the day and night are essential for at least 3 months. During daytime the patient should wear a push-up bra to maximally stabilize the breast and the scar. We do not recommend a regular sports bra, because the breast is squashed and subjected to pressure and thus increased tension on the scar; on the other hand, during the night 
an encapsulating sports bra is more convenient as it helps to stabilize the breast when the patient is lying on the back. Additional immobilization of the scar with Micropore ${ }^{\circledR}$ or Steristrips ${ }^{\circledR}$ helps to stabilize the scar during this period.

The combined measures described above help to immobilize the scar, diminish perpendicular tension, and increase tension in the line of the scar, and may result in a thin scar. We think that the theories of Kraissl and Langer are based on static observations and are lacking the biodynamic components in scarring. We therefore recommend adapting incision lines to the mentioned principles and to name them "BEST" lines (Biodynamic Excisional Skin Tension Lines) as recommended by Paul [6] for incisions on the lower limbs.

\section{Key Message}

The incision lines on the female breast according Langer and Kraissl are no longer adapted to new concepts in dermatosurgery because biomechanical principles, ageing, and ptosis of the female breast were not taken into account.

\section{Disclosure Statement}

The author declares no conflict of interest.

\section{Funding Sources}

The author has no funding sources to declare.

\section{References}

1 Langer K. "Zur Anatomie und Physiologie der Haut. Über die Spaltbarkeit der Cutis". Sitzungsbericht der Mathematisch-naturwissenschaftlichen Klasse der Wiener Kaiserlichen Akademie der Wissenschaften Abt. 44. 1861. German.

2 Borges AF. Relaxed skin tension lines (RSTL) versus other skin lines. Plast Reconstr Surg. 1984 Jan;73(1):144-50.
3 Kraissl CJ. The selection of appropriate lines for elective surgical incisions. Plast Reconstr Surg (1946). 1951 Jul;8(1):1-28.

4 Tomasek JJ, Gabbiani G, Hinz B, Chaponnier C, Brown RA. Myofibroblasts and mechanoregulation of connective tissue remodelling. Nat Rev Mol Cell Biol. 2002 May;3(5):349-63.

5 Bouffard NA, Cutroneo KR, Badger GJ, White SL, Buttolph TR, Ehrlich HP, et al. Tissue stretch decreases soluble TGF-betal and type-1 procollagen in mouse subcutaneous connective tissue: evidence from ex vivo and in vivo models. J Cell Physiol. 2008 Feb; 214(2):389-95.
6 Paul SP. Biodynamic excisional skin tension lines for excisional surgery of the lower limb and the technique of using parallel relaxing incisions to further reduce wound tension. Plast Reconstr Surg Glob Open. 2017 Dec; 5(12):e1614.

7 Regnault P. Breast ptosis. Definition and treatment. Clin Plast Surg. 1976 Apr;3(2): 193-203. 